\title{
The Determinants of Risk Premia in Forward Foreign Exchange (FX) Markets
}

\author{
Aziz Chouikh ${ }^{1} \&$ Abdelwahed Trabelsi ${ }^{2}$ \\ ${ }^{1}$ Department of Finance, Institut Supérieur d'Informatique et de Gestion, University of Kairouan, Kairouan, Tunisia \\ ${ }^{2}$ Department of Statistics, Institut Supérieur de Gestion, University of Tunis, Tunis, Tunisia \\ Correspondence: Aziz Chouikh, Institut Supérieur d'Informatique et de Gestion, University of Kairouan, Avenue \\ Khmaies El Alouini, 3100, Kairouan, Tunisia. Tel: 216-7-723-6571. E-mail: azizchouikh@gmail.com
}

Received: December 23, 2013

Accepted: January 21, $2014 \quad$ Online Published: March 30, 2014

doi:10.5430/ijfr.v5n2p19

URL: http://dx.doi.org/10.5430/ijfr.v5n2p19

\begin{abstract}
In this paper we reconsider the Fama (1984)'s seminal paper and we make extensions. We take into account for ARMA dynamics and ARCH-M effects in exchange rates and we introduce in equation regressions a proxy for the liquidity. We find out that the differenced relative bid-ask spread is a significant determinant of forward risk premia. In addition we evidence the outperformance of the multimarket hypothesis vs the single market hypothesis and the existence of common factors between forward risk premia in the EUR/USD, EUR/GBP and EUR/JPY forward exchange rates.
\end{abstract}

Keywords: ARMA, ARCH-M, liquidity, forward risk premia, multimarket hypothesis, single market hypothesis

\section{Introduction}

Academicians as well as practitioners are interested in studying and discovering the clues to the labyrinthine complexities of risk premia. They are the core of the theory of financial decision making. We will focus, in this paper, on the forward risk premium component in the FX market. It is important to find out the variables that explain significantly the forward risk premium. This is useful to understand its behavior, to test the FX market efficiency and to predict FX market movements. The financial theory suggests that exchange rates are related to domestic and foreign interest rates and precisely to their differentials. Covered as well as uncovered interest rate parity evidences this idea. In addition, a liquidity measure seems sine qua non to focus on the illiquidity risk in the pricing of forward exchange rates and therefore it is plausible to hypothesize that the forward risk premium is linked to the foreign currency liquidity (Note 1) measure. In fact either the trading volume (Note 2) or the relative bid-ask spread (Note 3) are good proxies for the liquidity measure. Moreover, the trade-off between risk and return is obvious. So it is plausible to insert a volatility measure (Note 4) to explain the forward risk premium. Fama (1984) evidenced that most of the variation in forward exchange rates is time variation in premiums. Olimov (2005) pointed out two main conclusions: both components of forward rates are time-varying and the variance of the forward risk premium is not large relative to the variance of the expected spot rates depreciation. Wolff (1987)'s findings supported the evidence of time-varying forward risk premia plus a certain degree of persistence in a signal extraction framework. In addition, Wolff (2000) evidenced statistically significant time-variation and persistence of the risk premium component and found out that the variability of the risk premium is reliably less than the variability of the forward forecast error. Yu, Fung, and Hongyi (2005) evidenced a time-varying forward risk premium component and mentioned that the forward exchange rates, after taking into account the forward risk premium, are not optimal predictors of the future spot exchange rates. Bidarkota (2004) found a significant time-varying forward risk premia. Wang and Bidarkota (2012) evidenced the existence of time-varying risk premia in forward rates that make them biased predictors of the future spot rate. But none of them has introduced a measure of liquidity in his model. We will investigate into the eventual determinants of risk premia in forward FX markets. Our paper will be organized as follows. Section 2 deals with a typology of the determinants of forward risk premium components. Section 3 presents candidate models and their financial foundations. Section 4 conceptualizes the empirical framework. Finally, in section 5 we will point out the regression results and their interpretations. 


\section{A Typology of the Determinants of Forward Risk Premium Components}

If we model the forward risk premium as an observed component, we will have to model the forward premium (Note 5). However, if we model it as an unobserved component, we will explain it via observed variables that contain themselves the unobserved signal. It is obvious that the choice depends on the arbitrariness of the econometrician. However, it is plausible that the significance of a determinant should be independent of modeling the signal. We will try to explain the unobserved forward risk premium via observed variables containing the underlying signal. It follows that the exogenous or the endogenous variable has to contain the unobserved forward risk premium.

\subsection{The Forward-spot Differential (Note 6)}

It is the difference, at time t, between the forward exchange rate and the spot exchange rate. The underlying foreign currency is said to be, respectively, in the money, at the money or out of the money if and only if $f_{t, 1, i}-S_{t, i}>$ $0, f_{t, 1, i}-S_{t, i}=0$ or $f_{t, 1, i}-S_{t, i}<0$. The sign of the forward premium gives us information about the difference between the domestic and the foreign interest rates. It follows that having information about the former is equivalent to having information about the latter. Then it is redundant to introduce in the same regression equation model both the the forward-spot differential and the interest rates differential. Otherwise, a multicollinearity problem will arise. In addition, this variable contains the underlying forward risk premium which is the core of our analysis. Given the assumption that the forward risk premium is an unobserved variable, we must use observed variables that can help us to find out its determinants. The forward discount is an observed variable that enables us to deepen our understanding about forward risk premium in the pricing of forward exchange rates.

\subsection{The Relative Bid-ask Spread}

The forward risk premium may be composed of two components: the first component is related to the exchange rate risk, while the second is related to the illiquidity risk. Then, it is important to understand how the forward risk premium behaves with respect to liquidity fluctuations. Therefore, it seems plausible to define a measure of liquidity and use it as an exogenous variable in our regressions (Note 7). We will test the explanatory power of this underlying measure with respect to the forward risk premium. We choose the relative bid-ask spread (Note 8) as a liquidity proxy for the following reasons: First, the availability of data. In fact, we have bid and ask quotes for both the forward and the spot exchange rates but we do not have the trading volume data. Second, according to the financial literature, as reported by Mamoghli and Henchiri (2002), the relative bid-ask spread (Note 9) is a function of the trading volume. It follows that using the former or the latter in our models is equivalent.

\subsection{The Exchange Rate Volatility}

We cannot talk about return without talking about risk and vice versa. The risk-return trade-off is the cornerstone of the theory in/of finance. We are unable to explain the return process without focusing on the risk. The exchange rate volatility expresses the foreign exchange risk due to price fluctuations over time. In addition, the empirical literature has evidenced the time variation of both risk and return. This implies that we have to model this time variation of the exchange rate volatility.

\section{Candidate Models and Their Financial Foundations}

\subsection{Individual Regression Models}

This class of regression models does not take into account the interaction between the foreign currencies. In fact, for each foreign currency, a model will be run separately. This corresponds to the single market hypothesis. Two kinds of models will be set up: the regressions using dependent and independent variables without any dynamics and the regressions using ARMA (Note 10) dynamics. This class of time series models signifies that past realizations of the dependent variable and errors are deemed as determinants.

\subsection{The SURE (Note 11) Model}

All foreign currencies are considered jointly and not separately. So the equations are estimated simultaneously pointing out the interactions between the foreign currencies and the residuals. We will focus on the SURE method (Note 12). It takes into account the interaction between the foreign currencies (Note 13) and considers that the endogenous variables are related only by the errors variance-covariance matrix. This corresponds to the multimarket hypothesis which is more realistic in an economic world where each investor introduces all foreign currencies prices into his information set.

\subsection{The Univariate (G)ARCH-(M) Model}

The theoretical relationship between risk and return over time is obvious. The (G)ARCH-(M) models (Note 14) 
family with all its extensions satisfies this underlying relationship. In fact, this class of models underlines the time-varying feature of volatility which is sine qua non in our empirical work. To correct specifications of volatility is essential. We will reestimate Fama's regressions introducing this kind of dynamics.

\section{The Empirical Framework}

\subsection{Data and Underlying Variables}

We consider three foreign currencies bilateral to the Euro: the USD, the JPY and the GBP. We deal with daily spot foreign exchange rates and daily one-week forward exchange rates. The sample is from 01/01/1999 to 12/01/2006 which gives us 2066 observations (Note 15). In addition, the neperian logarithm of exchange rates is used to avoid the Siegel's paradox arising from the Jensen's inequality. Furthermore, we deal with overlapping data (Note 16). The variables we deal with are: $f_{t, 1, i}-S_{t+1, i}$ will be referred to as $Y_{W U S D} D_{t+1}, Y_{W G B P}$ and $Y_{t+1}$ JPYY $t_{t+1} \cdot f_{t, 1, i}-S_{t, i}$ will be $\mathrm{XWUSD}_{\mathrm{t}}, \mathrm{XWGBP}_{\mathrm{t}}$ and $\mathrm{XWJPY}_{\mathrm{t}}$. $\mathrm{S}_{\mathrm{t}+1, \mathrm{i}}-\mathrm{S}_{\mathrm{t}, \mathrm{i}}$ will be symbolized by DWSUSD $\mathrm{t}_{\mathrm{t}+1}, \mathrm{DWSGBP}_{\mathrm{t}+1}$ and

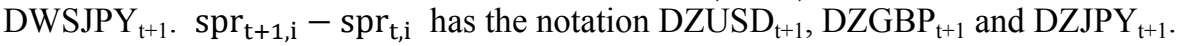

\subsection{The Methodology}

We will run estimations using Fama's regressions (Note 17) as a starting point and our alternative regressions and we will make comparisons between results. In addition, we will introduce ARMA and (G)ARCH-(M) dynamics to Fama's regressions. Furthermore, we have had the idea to introduce a variable that reflects the liquidity in Fama's equations. This is very salient because, theoretically, it should be. We will run individual regression models as well as SURE models, based on Fama's decomposition and our alternative decomposition. Here are, respectively, the underlying decompositions (Note 18):

$$
\begin{gathered}
\mathrm{f}_{\mathrm{t}, 1, \mathrm{i}}-\mathrm{S}_{\mathrm{t}, \mathrm{i}}=\mathrm{f}_{\mathrm{t}, 1, \mathrm{i}}-\mathrm{S}_{\mathrm{t}+1, \mathrm{i}}+\mathrm{S}_{\mathrm{t}+1, \mathrm{i}}-\mathrm{S}_{\mathrm{t}, \mathrm{i}} \\
\mathrm{f}_{\mathrm{t}, 1, \mathrm{i}}-\mathrm{S}_{\mathrm{t}+1, \mathrm{i}}=\mathrm{f}_{\mathrm{t}, 1, \mathrm{i}}-\mathrm{S}_{\mathrm{t}, \mathrm{i}}-\left(\mathrm{S}_{\mathrm{t}+1, \mathrm{i}}-\mathrm{S}_{\mathrm{t}, \mathrm{i}}\right)
\end{gathered}
$$

An obvious question is: why do we think about an alternative decomposition? The Fama's decomposition leads to a system of equivalent regression equations wherein we deal with lagged variables (Note 19). So we propose an alternative decomposition wherein there is an equation dealing with explanatory and explained variables measured at the same time. Indeed, the Fama's decomposition leads to the following system of equivalent regressions that we call, hereafter, Fama's regressions:

$$
\text { System 1: }\left\{\begin{array}{l}
\mathrm{f}_{\mathrm{t}, 1, \mathrm{i}}-\mathrm{S}_{\mathrm{t}+1, \mathrm{i}}=\mathrm{a}_{1}+\mathrm{a}_{2}\left(\mathrm{f}_{\mathrm{t}, 1, \mathrm{i}}-\mathrm{S}_{\mathrm{t}, \mathrm{i}}\right)+\varepsilon_{\mathrm{t}+1} \\
\mathrm{~S}_{\mathrm{t}+1, \mathrm{i}}-\mathrm{S}_{\mathrm{t}, \mathrm{i}}=\mathrm{a}_{3}+\mathrm{a}_{4}\left(\mathrm{f}_{\mathrm{t}, 1, \mathrm{i}}-\mathrm{S}_{\mathrm{t}, \mathrm{i}}\right)+\mu_{\mathrm{t}+1}
\end{array}\right.
$$

Whereas, our decomposition leads to the following system

$$
\text { System } 2:\left\{\begin{array}{l}
f_{\mathrm{t}, 1, \mathrm{i}}-\mathrm{S}_{\mathrm{t}, \mathrm{i}}=\mathrm{d}_{1}+\mathrm{d}_{2}\left(\mathrm{f}_{\mathrm{t}, 1, \mathrm{i}}-\mathrm{S}_{\mathrm{t}+1, \mathrm{i}}\right)+v_{\mathrm{t}+1} \\
\mathrm{~S}_{\mathrm{t}+1, \mathrm{i}}-\mathrm{S}_{\mathrm{t}, \mathrm{i}}=\mathrm{d}_{3}+\mathrm{d}_{4}\left(\mathrm{f}_{\mathrm{t}, 1, \mathrm{i}}-\mathrm{S}_{\mathrm{t}+1, \mathrm{i}}\right)+\eta_{\mathrm{t}+1}
\end{array}\right.
$$

In System 1, the intercept estimates sum to zero, the slope coefficient estimates sum to one and the sum of residuals is zero on a period-by-period basis. While, in System 2, the difference between the intercept estimates equals zero, the difference between the slope coefficient estimates equals one and the difference between residuals equals zero on a period-by-period basis. In both equations of System 1, both exogenous and endogenous variables are not observed at the same time, however in System 2 equation (4.2) both the explained and the explanatory variables are measured at the same time. Here are the following steps (Note 20) that express our methodology. In step 0, we run the unit root tests (Note 21) for all variables. In step 1, we run the estimation of Fama's regressions. In step 2, we run the estimation of our alternative regressions. In step 3, we introduce ARMA dynamics. In step 4, we introduce (G)ARCH-(M) dynamics. In step 5, we introduce the liquidity proxy into (G)ARCH-(M) models. In step 6, we run the estimation of a SURE model using Fama's decomposition. Finally, in step 7 we run the estimation of a SURE model using our alternative equations (Note 22).

\section{Regression Results and Interpretations}

\subsection{Individual Regressions}

\subsubsection{EUR/USD}

According to Fama [2], the regressions (Note 23) we run are the following:

$$
\begin{aligned}
& \text { YWUSD }_{t+1}=a_{1, \text { USD }}+a_{2, U S D} X_{\text {WUSD }}+\varepsilon_{t+1, U S D} \\
& \text { DWSUSD }_{t+1}=a_{3, U S D}+a_{4, U S D} X W U S D_{t}+\mu_{t+1, U S D}
\end{aligned}
$$

We find out that the intercept estimate, $\hat{a}_{1, \text { USD }}$, is not statistically significant at $1 \%$ and $5 \%$ levels (Note 24$)$. Then we estimate the regression equation without an intercept. 
Table 1. The estimation of equation (5)

\begin{tabular}{cccccc}
\hline$\hat{\mathrm{a}}_{2, \text { USD }}$ & Standard error & t-statistic & $\mathrm{p}$-value & $\mathrm{R}^{2}$ & Adjusted $^{2}$ \\
\hline 3.585098 & 1.255765 & 2.854912 & 0.0043 & 0.009225 & 0.009225 \\
\hline
\end{tabular}

As shown in Table 1, the slope coefficient estimate (Note 25 ), $\hat{a}_{2, \text { USD }}$, is statistically significant at $1 \%$ level, positive and greater than one (Note 26). Then the forecast error of using the forward exchange rate as a predictor of the future spot exchange rate is elastic to variations in the forward-spot differential. The statistical significance of $\hat{a}_{2, \text { USD }}$ means that the forward exchange risk premium, $\mathrm{P}_{\mathrm{t}, 1}$, of the forward-spot differential, $\mathrm{XWUSD}_{\mathrm{t}}$, has variation that shows up significantly in the dependant variable, YWUSD ${ }_{t+1}$. A positive slope coefficient implies that $f_{t, 1}-S_{t+1}=P_{t, 1}+$ $\mathrm{E}\left(\mathrm{S}_{\mathrm{t}+1} / \psi_{t}\right)-\mathrm{S}_{\mathrm{t}+1}$ is an increasing function of the forward discount which means, given that the forecast error tends to converge to zero according to learning effect within an efficient FX market where agents are rational and use all the available information to make expectations, that the forward risk premium is significantly an increasing function of the forward premium. The fact that $\hat{\mathrm{a}}_{2, \mathrm{USD}}>1$ signifies that $\hat{\mathrm{a}}_{4, \mathrm{USD}}<0$ given that $\hat{\mathrm{a}}_{2, \mathrm{USD}}+\hat{\mathrm{a}}_{4, \mathrm{USD}}=1$ : $\hat{\mathrm{a}}_{4, \mathrm{USD}}<0$ reflects a negative covariance between the forward risk premium and the conditional expectation of the appreciation/depreciation of the spot exchange rate and this covariance is greater in absolute magnitude than the variance of the conditional expectation of appreciation/depreciation of the spot exchange rate. In addition we have $\hat{a}_{2, \text { USD }}-\hat{a}_{4, \text { USD }}>0$ which implies that the variance of the forward risk premium is greater than the variance of the conditional expectation of the appreciation/depreciation of the spot exchange rate. We estimate, now, our alternative regressions (Note 27).

Table 2. The estimation of equation (4.2)

\begin{tabular}{ccc}
\hline Coefficient estimate & Value & p-value \\
\hline$\widetilde{d}_{3, U S D}$ & $9.96 \times 10^{-5}$ & 0.0000 \\
$\widetilde{d}_{4, U S D}$ & -0.997253. & 0.0000 \\
\hline
\end{tabular}

As shown in Table 2, both the intercept and slope coefficient estimates are reliably different from zero at $1 \%$ level. The statistical significance of $\tilde{d}_{4, U S D}$ means that the forward risk premium, $P_{t, 1}$, buried in YWUSD $D_{t+1}$, has variation that shows up significantly in the dependant variable, DWSUSD ${ }_{t+1}$. The slope coefficient estimate is also statistically negative at $1 \%$ level. A negative slope coefficient estimate implies that DWSUSD $_{t+1}$ is a decreasing function of YWUSD $_{t+1} . \tilde{d}_{4, U S D}$ is nearby -1 but greater than -1 . Then we run the Wald test for the null hypothesis $\mathrm{H}_{0}$ : $\tilde{\mathrm{d}}_{4, \mathrm{USD}}=$ -1 vs $\mathrm{H}_{\mathrm{A}}: \mathrm{d}_{4, \mathrm{USD}} \neq-1$.

Table 3. Wald test

\begin{tabular}{cccc}
\hline Test statistic & Value & $\mathrm{df}$ & Probability \\
\hline F-statistic & 24.5777 & $(1 ; 2064)$ & 0.0000 \\
$\chi^{2}$-statistic & 24.5777 & 1 & 0.0000 \\
\hline
\end{tabular}

As shown in Table 3, we reject the null at 5\% level given that the probability is less than 0.05 . Thus we have statistically and significantly $-1<\tilde{\mathrm{d}}_{4, \mathrm{USD}}<0 \Leftrightarrow 0<\tilde{\mathrm{d}}_{2, \mathrm{USD}}<1 \Leftrightarrow \hat{\mathrm{a}}_{2, \mathrm{USD}}>0$ which is found out. We can reliably deduce that our alternative regressions are coherent with Fama's regressions. Now, we diagnose the SACF and SPACF of the dependent variable time series $\left(. \mathrm{YWUSD}_{\mathrm{t}+1}\right)$. We find out significant autocorrelations given by the SACF, of order four, and SPACF, of order two. Thus we reestimate the regression equation introducing ARMA dynamics. When we introduce either AR or MA dynamics or both, the explanatory power of $\mathrm{XWUSD}_{t}$ vanishes and its coefficient estimate, $\hat{a}_{2, U S D}$, becomes statistically insignificant. The best ARMA model (Note 28) we find out is a MA(4) model. The correlogram of squared residuals supports the statistical significance of autocorrelations in squared residuals. This is reliably confirmed by the ARCH-LM test. Our model identification procedure leads to reliably two models: ARCH(1) model (Note 29) and ARCH(1)-M (Note 30). In both models the differenced relative bid-ask spread, DZUSD, is statistically significant as a regressor in the variance equation. This empirical evidence shows up reliably 
that the liquidity (illiquidity) affects the return via the conditionl time-varying volatility and not directly. The liquidity (illiquidity) is a determinant of the conditionally heteroskedastic volatility. We get these models (Note 31):

$$
\begin{aligned}
& \text { Mean equation: YWUSD } \\
& \text { Vart+1 }=4.826012 X_{\text {XWUSD }}+\varepsilon_{t+1, U S D} \\
& \text { Mean equation: YWUSD } \mathrm{h}_{\mathrm{t}+1}=5.389249 \mathrm{XWUSD}_{\mathrm{t}}+0.000109 \mathrm{Ln}\left(\mathrm{h}_{\mathrm{t}+1, \mathrm{USD}}\right)+\varepsilon_{\mathrm{t}+1, \mathrm{USD}} \\
& \text { Variance equation: } \mathrm{h}_{\mathrm{t}+1, \mathrm{USD}}=6.24 \times 10^{-5}+0.682075 \varepsilon_{\mathrm{t}, \mathrm{USD}}^{2}-0.051573 \mathrm{SZUSD}_{\mathrm{t}+1}
\end{aligned}
$$

The differenced relative bid-ask spread coefficient estimate is negative and less than one in absolute value (Note 32 ). So more the foreign currency is illiquid more its conditionally heteroskedastic volatility is decreasing and vice versa and this empirical result is in line with the theory. In addition, an increase (a decrease) of $1 \%$ in EUR/USD conditionally heteroskedastic variance, according to the second model, necessitates a decrease (an increase) of $19.39 \%$ in the differenced relative bid-ask spread. In the $\mathrm{ARCH}(1)$ model, we find out the following inference: more the differenced relative bid-ask spread increases more the conditionally heteroskedastic volatility decreases which signifies that more the elasticity of the ask spot exchange rate to the bid spot exchange rate increases more the conditionally heteroskedastic volatility decreases. In the $\mathrm{ARCH}(1)-\mathrm{M}$ model, we find out the following inference: more the differenced relative bid-ask spread increases more the conditionally heteroskedastic volatility decreases and so more YWUSD also decreases. So more the elasticity of the ask spot rate to the bid spot rate increases more YWUSD decreases.

\subsubsection{EUR/GBP}

The same reasoning is applied. The starting point is Fama's regression equations (Note 33) for the EUR/GBP. We find out that the first regression intercept term is not statistically significant and the slope coefficient estimate, $\hat{a}_{2, \mathrm{GBP}}$, is statistically significant at $1 \%$ level, positive and greater than one (Note 34 ).

Table 4. The estimation of equation (8) (Note 35)

\begin{tabular}{crrrrr}
\hline$\hat{\mathrm{a}}_{2, \mathrm{GBP}}$ & Standard error & t-statistic & $\mathrm{p}$-value & $\mathrm{R}^{2}$ & Adjusted $\mathrm{R}^{2}$ \\
\hline 1.713513 & 0.541187 & 3.166214 & 0.0016 & 0.002566 & 0.002566
\end{tabular}

The estimation of our alternative regression equation (Note 36 ) points out statistically significant intercept and slope coefficient estimates (Note 37).

Table 5. The estimation of equation (4.2)

\begin{tabular}{ccc}
\hline Coefficient estimate & Value & p-value \\
\hline$\tilde{d}_{3, G B P}$ & $3.27 \times 10^{-4}$ & 0.0000 \\
$\widetilde{d}_{4, G B P}$ & -0.998836 & 0.0000
\end{tabular}

$\widetilde{\mathrm{d}}_{4, \mathrm{GBP}}$ is nearby -1 but greater than -1 . Then we run the Wald test for the null hypothesis $\mathrm{H}_{0}: \widetilde{\mathrm{d}}_{4, \mathrm{GBP}}=-1$ vs $\mathrm{H}_{\mathrm{A}}$ : $\tilde{\mathrm{d}}_{4, \mathrm{GBP}} \neq-1$.

Table 6. Wald test

\begin{tabular}{cccc}
\hline Test statistic & Value & df & Probability \\
\hline F-statistic & 8.74301 & $(1 ; 2064)$ & 0.0031 \\
$\chi^{2}$-statistic & 8.74301 & 1 & 0.0031
\end{tabular}

As shown above, we reject the null at $5 \%$ level given that the probability is less than 0.05 . Thus we have statistically and significantly $-1<\widetilde{\mathrm{d}}_{4, \mathrm{GBP}}<0 \Leftrightarrow 0<\tilde{\mathrm{d}}_{2, \mathrm{GBP}}<1 \Leftrightarrow \hat{\mathrm{a}}_{2, \mathrm{GBP}}>0$ which is found out (Note 38 ). Now, we diagnose the SACF and SPACF of the dependent variable time series $\left(\mathrm{YWGBP}_{\mathrm{t}+1}\right)$. We find out significant autocorrelations given by the SACF, of order four, and SPACF, of order two. Thus we reestimate the regression equation introducing ARMA dynamics. When we introduce either AR or MA dynamics (Note 39) or both, the explanatory power of XWGBP vanishes and its coefficient estimate, $\hat{\mathrm{a}}_{2, \mathrm{GBP}}$, becomes statistically insignificant. Similar to the case of EUR/USD, the best ARMA model we evidence is a MA(4) model and ARCH effects are statistically significant. Our model identification procedure leads to reliably $\mathrm{ARCH}(1)$ (Note 40) and $\mathrm{ARCH}(1)-\mathrm{M}$ (Note 41) models. The differenced relative bid-ask spread, DZGBP, is statistically significant as a regressor only in the variance equation of the ARCH(1)-M model. We get: 


$$
\begin{gathered}
\text { Mean equation: YWGBP } \\
\text { Vart+1 } \\
\text { Vance equation: } \mathrm{h}_{\mathrm{t}+1, \mathrm{GBP}}=3.333185 \mathrm{XWGBP}_{\mathrm{t}}+\varepsilon_{\mathrm{t}+1, \mathrm{GBP}} \\
\text { Mean equation: } \mathrm{YWGBP}_{\mathrm{t}+1}=0.001774-6.516720 \mathrm{~h}_{\mathrm{t}+1, \mathrm{GBP}}+\varepsilon_{\mathrm{t}+1, \mathrm{GBP}} \\
\text { Variance equation: } \mathrm{h}_{\mathrm{t}+1, \mathrm{GBP}}=3.22 \times 10^{-5}+0.624083 \varepsilon_{\mathrm{t}, \mathrm{GBP}}^{2}-0.011343 \mathrm{DZGBP} \mathrm{t}_{\mathrm{t}+1}
\end{gathered}
$$

The differenced relative bid-ask spread coefficient estimate is negative and less than one in absolute value. So more the foreign currency is illiquid more its conditionally heteroskedastic volatility is decreasing and vice versa and this empirical result is in line with the theory. In addition, an increase (a decrease) of $1 \%$ in EUR/GBP conditionally heteroskedastic variance necessitates a decrease (an increase) of $88.16 \%$ in the differenced relative bid-ask spread. We can infer that more the differenced relative bid-ask spread increases more the conditionally heteroskedastic volatility decreases and so more YWGBP increases which signifies that more the elasticity of the ask spot exchange rate to the bid spot exchange rate increases more YWGBP also increases. We have a negative coefficient estimate of the conditionally heteroskedastic variance. It follows that YWGBP is negatively sensitive to the conditional time-varying variance.

\subsubsection{EUR/JPY}

The estimation of the equation (Note 42) (5) evidences the statistical insignificance of XWJPY (Note 43). So we estimate our alternative regression based on the decomposition given by equation (2). It follows:

$$
\operatorname{DWSJPY}_{\mathrm{t}+1}=\mathrm{d}_{3, \mathrm{JPY}}+\mathrm{d}_{4, \mathrm{JPY} Y W J P Y_{\mathrm{t}+1}}+\eta_{\mathrm{t}+1, \mathrm{JPY}}
$$

Table 7. The estimation of equation (12)

\begin{tabular}{ccc}
\hline Coefficient estimate & Value & p-value \\
\hline$\widetilde{d}_{3, J P Y}$ & $5.67 \times 10^{-4}$ & 0.0000 \\
$\tilde{d}_{4, J P Y}$ & -0.999586 & 0.0000 \\
\hline
\end{tabular}

As it is shown above, bBoth the intercept and slope coefficient estimates are reliably non zero at $1 \%$ level. In fact, $\widetilde{\mathrm{d}}_{4, \mathrm{JPY}}=-0.999586$. Then we run the Wald test for the null hypothesis $\mathrm{H}_{0}: \widetilde{\mathrm{d}}_{4, \mathrm{GBP}}=-1$ vs $\mathrm{H}_{\mathrm{A}}: \widetilde{\mathrm{d}}_{4, \mathrm{GBP}} \neq-1$.

Table 8. Wald test

\begin{tabular}{cccc}
\hline Test statistic & Value & $\mathrm{df}$ & Probability \\
\hline F-statistic & 1.861244 & $(1 ; 2064)$ & 0.1726 \\
$\chi^{2}$-statistic & 1.861244 & 1 & 0.1726 \\
\hline
\end{tabular}

As shown above, we accept the null at $5 \%$ level given that the probability is more than 0.05 . This result is of most importance because it explains why the basic Fama's model is misspecified. Our alternative regression supports the empirical result that XWJPY is statistically constant over time (Note 44). Now, we diagnose the serial autocorrelations in the dependent variable time series, $\left(\mathrm{YWJPY}_{\mathrm{t}+1}\right)$ and introduce the remaining explanatory variables. The SACF and SPACF evidence ARMA dynamics. The MA(4) model well represents the underlying time series (Note 45). In addition, the ARCH-LM test supports the existence of reliably ARCH effects (Note 46). Then we estimate a MA(4)-ARCH(1) (Note 47) model. We find out the following estimated model:

$$
\begin{gathered}
\mathrm{YWJPY}_{\mathrm{t}+1, \mathrm{JPY}}=\varepsilon_{\mathrm{t}+1, \mathrm{JPY}}-0.97775 \varepsilon_{\mathrm{t}, \mathrm{PPY}}-0.96301 \varepsilon_{\mathrm{t}-1, \mathrm{PPY}}-0.96277 \varepsilon_{\mathrm{t}-2, \mathrm{PPY}}-0.9409 \varepsilon_{\mathrm{t}-3, \mathrm{JPY}} \\
\mathrm{h}_{\mathrm{t}+1, \mathrm{JPY}}=4.29 \times 10^{-5}+0.150112 \varepsilon_{\mathrm{t}, \mathrm{PY}}^{2}
\end{gathered}
$$

\subsection{SURE Models}

We calculate the correlation matrices between the underlying foreign currencies for each variable. If interactions are statistically significant, we set up the SURE method based on Fama's decomposition and our alternative decomposition (Note 48). We find out significant correlations (Note 49). So we run the Zellner's regressions.

$$
\left(\begin{array}{c}
Y W U S D_{t+1} \\
Y W G B P_{t+1} \\
Y W J P Y_{t+1}
\end{array}\right)=\left(\begin{array}{c}
a_{1, U S D} \\
a_{1, G B P} \\
a_{1, J P Y}
\end{array}\right)+\left(\begin{array}{ccc}
X W U S D_{t} & 0 & 0 \\
0 & X W G B P_{t} & 0 \\
0 & 0 & X W J P Y_{t}
\end{array}\right)\left(\begin{array}{l}
a_{2, U S D} \\
a_{2, G B P} \\
a_{2, J P Y}
\end{array}\right)+\left(\begin{array}{c}
\varepsilon_{t+1, U S D} \\
\varepsilon_{t+1, G B P} \\
\varepsilon_{t+1, J P Y}
\end{array}\right)
$$




$$
\left(\begin{array}{l}
D W S U S D_{t+1} \\
D W S G B P_{t+1} \\
D W S J P Y_{t+1}
\end{array}\right)=\left(\begin{array}{c}
d_{3, U S D} \\
d_{3, G B P} \\
d_{3, J P Y}
\end{array}\right)+\left(\begin{array}{ccc}
Y W U S D_{t+1} & 0 & 0 \\
0 & Y W G B P_{t+1} & 0 \\
0 & 0 & Y W J P Y_{t+1}
\end{array}\right)\left(\begin{array}{l}
d_{4, U S D} \\
d_{4, G B P} \\
d_{4, J P Y}
\end{array}\right)+\left(\begin{array}{l}
\eta_{t+1, U S D} \\
\eta_{t+1, G B P} \\
\eta_{t+1, J P Y}
\end{array}\right)
$$

Table 9. The estimation of equation (15)

\begin{tabular}{crrrrrr}
\hline & \multicolumn{1}{c}{$\hat{\mathrm{a}}_{1, \mathrm{USD}}$} & \multicolumn{1}{c}{$\hat{\mathrm{a}}_{2, \mathrm{USD}} \cdot$} & \multicolumn{1}{c}{$\hat{\mathrm{a}}_{1, \mathrm{GBP}} \cdot$} & \multicolumn{1}{c}{$\hat{\mathrm{a}}_{2, \mathrm{GBP}}$} & $\hat{\mathrm{a}}_{1, \mathrm{JPY} \cdot}$ & $\hat{\mathrm{a}}_{2, \mathrm{JPY}} \cdot$ \\
\hline Coeff estimate & -0.000473 & 2.707781 & -0.000237 & 2.075399 & 0.000219 & 2.034726 \\
Standard error & 0.000304 & 0.648322 & 0.000363 & 0.90122 & 0.000474 & 0.575334 \\
t-statistic & -1.557379 & 4.176601 & -0.65383 & 2.302877 & 0.461447 & 3.536601 \\
p-value & 0.1194 & 0.0000 & 0.5132 & 0.0213 & 0.6445 & 0.0004 \\
\hline
\end{tabular}

As shown in Table 9, all the intercept term estimates of equation (15) are not statistically significant. Then we reestimate the same regression equation (15) without intercept terms.

Table 10. The estimation of equation (15) without intercept terms

\begin{tabular}{crrr}
\hline & \multicolumn{1}{c}{$\hat{\mathrm{a}}_{2, \mathrm{USD}} \cdot$} & $\hat{\mathrm{a}}_{2, \mathrm{GBP}} \cdot$ & \multicolumn{1}{c}{$\hat{\mathrm{a}}_{2, \mathrm{JPY}} \cdot$} \\
\hline Coeff estimate & 2.354196 & 1.832523 & 1.499258 \\
Standard error & 0.613338 & 0.461948 & 0.370582 \\
t-statistic & 3.838331 & 3.966945 & 4.045683 \\
p-value & 0.0001 & 0.0001 & 0.0001
\end{tabular}

All coefficient estimates are reliably non zero at $1 \%$ level and greater than one. When we estimate separately the foreign currencies we find out a statistically insignificant slope coefficient estimate $\hat{a}_{2, J P Y}$. However, when we estimate them jointly we find out a statistically significant slope coefficient estimate (Note 50) $\hat{a}_{2, J P Y}$. The SURE method improves empirical results. Moreover, we have both $\hat{a}_{2, \mathrm{GBP}}$ and $\hat{\mathrm{a}}_{2, \mathrm{JPY}}$ greater than one and less than two which incites us to ask for their statistical equality. Thus we run the Wald test for the null hypothesis $\mathrm{H}_{0}$ : $\hat{\mathrm{a}}_{2, \mathrm{GBP}}=$ $\hat{a}_{2, \mathrm{JPY}}$ Vs $\mathrm{H}_{\mathrm{A}}: \hat{\mathrm{a}}_{2, \mathrm{GBP}} \neq \hat{\mathrm{a}}_{2, \mathrm{JPY}}$.

Table 11. Wald test

\begin{tabular}{cccc}
\hline Test statistic & Value & df & Probability \\
\hline$\chi^{2}$-statistic & 0.289488 & 1 & 0.5905
\end{tabular}

As shown above, we accept the null at 5\% level given a probability greater than 0.05 . It shows up reliably that the EUR/GBP and EUR/JPY have common factors when considered jointly. Now we estimate equation (16). We get the following output:

Table 12. The estimation of equation (16)

\begin{tabular}{crrrrrr}
\hline & \multicolumn{1}{c}{$\tilde{\tilde{d}}_{3, U S D}$} & $\tilde{\tilde{d}}_{4, U S D}$ & $\tilde{\tilde{d}}_{3, G B P}$ & \multicolumn{1}{c}{$\tilde{d}_{4, G B P} \cdot$} & $\tilde{\tilde{d}}_{3, J P Y} \cdot$ & $\tilde{d}_{4, J P Y} \cdot$ \\
\hline Coeff estimate & $9.94 \times 10^{-5}$ & -0.998376 & 0.000328 & -0.999108 & -0.000568 & -1.000263 \\
Standard error & $7.75 \times 10^{-6}$ & 0.000445 & $4.39 \times 10^{-6}$ & 0.000322 & $1.06 \times 10^{-5}$ & 0.000596 \\
t-statistic & 12.82388 & -2243.406 & 74.59431 & -3099.545 & -53.40378 & -1679.183 \\
p-value & 0.0000 & 0.0000 & 0.0000 & 0.0000 & 0.0000 & 0.0000
\end{tabular}

As shown in Table 12, we evidence statistically significant estimates at 1\% level. We find also that that EUR/USD and EUR/GBP have common factors (Note 51) according to Wald test as shown in Table 13 below:

Table 13. Wald test: $\mathrm{H}_{0}: \widetilde{m}_{4, U S D}=\widetilde{d}_{4, G B P}$ vs $\mathrm{H}_{\mathrm{A}}: \tilde{d}_{4, U S D} \neq \widetilde{\tilde{d}}_{4, G B P}$

\begin{tabular}{cccc}
\hline Test statistic & Value & df & Probability \\
\hline$\chi^{2}$-statistic & 2.744129 & 1 & 0.0976 \\
\hline
\end{tabular}




\section{Conclusion}

We model the forward risk premium component as an unobserved component of the forward exchange rate and WE explain it via observed variables. We make extensions based on Fama's [2] paper. We involve the conditionally heteroskedastic volatility, the forward discount, the differenced relative bid-ask spread and the forecast error of using the forward exchange rate as a predictor of the future spot exchange rate as explanatory variables and we test their statistical significance. We introduce eventual ARMA dynamics and ARCH-(M) effects whether they are statistically significant. We find out that the forward discount lose completely its significance whenever we involve other regressors. We also test the relevance or irrelevance of the liquidity measure proxy in our models. We support the evidence that this determinant is relevant either in the variance equation or the mean equation. We relate, in our empirical interpretation, the forward exchange risk premium component to the elasticity of the ask exchange rate to the bid exchange rate via the sign of the coefficient estimate of the differenced relative bid-ask spread. We evidence that the forward risk premium is time-varying and so does the expected exchange spot appreciation or depreciation. However, we can not judge whether the forward exchange risk premium is more variable than the expected exchange spot appreciation or depreciation or vice versa. Dealing with foreign exchange rates, the empirical researcher may decide to consider them either separately or jointly. We try both cases and we point out that the multimarket hypothesis outperforms the single market hypothesis. Our results are coherent with Fama's results and whenever we make SURE estimations some foreign currencies exhibit common factors (Note 52).

\section{Acknowledgements}

We would like to thank the referees at the TSFS (Tunisian Society for Financial Studies) first conference $\left(12^{\text {th }}-13^{\text {th }}\right.$ December 2013, Sousse, Tunisia) for helpful comments and criticism.

\section{References}

Bidarkota, Prasad V. (2004). Risk Premia in Forward Foreign Exchange Markets: A Comparison Signal Extraction and Regression Methods. Working Paper, Department of Economics, Florida International University, August 19 2004.

Fama, Eugene F. (1984). Forward and Spot Exchange Rates. Journal of Monetary Economics, 14, 319-338.

Mamoghli, Chokri, \& Henchiri Hanène. (2002). Microstructure du Marché des Changes Interbancaire Tunisien: Les Déterminants de la Fourchette des Prix. l'Actualité Economique, Revue d'Analyse Economique, 78(2).

Nijman, Theo E., Franz C. Palm, \& Christian, C.P. Wolff. (1993). Premia in Forward Foreign Exchange as Unobserved Components: A note. Journal of Business and Economic Statistics, 11(3), 361-365.

Olimov, Ulugbek E. (2005). Forward and Spot Exchange Rates by Fama (1984) Revisited. Working Paper, presented for the course "Seminar on International Finance" at the Graduate School of Humanities and Social Sciences, University of Tsukuba, Japan.

Wang, Zhiguang, \& Prasad V. Bidarkota. (2012). Risk Premium in Forward Foreign Exchange Rates: A Comparison of Signal Extraction and Regression Models. Empir Econ, 42, 21-51.

Wolff, Christian C.P. (1987). Forward Foreign Exchange Rates, Expected Spot Rates, and Premia: A Signal-Extraction Appraoch. The Journal of Finance, 42(2), 395-406.

Wolff, Christian C.P. (2000). Measuring the Forward Foreign Exchange Risk Premium: Multi-Country Evidence from Unobserved Components Models. Journal of International Financial Markets, Institutions and Money, 10, 1-8.

Yu, Ip-Wing, Laurence, Fung, \& Chen, Hongyi. (2005). Exchange Rate Risk Premiums in Hong Kong Dollar: A Signal-Extraction Approach. Working Paper, Hong Kong Monetary Authority, Research Memorandum 18/2005, November 2005.

\section{Notes}

Note 1. Or illiquidity.

Note 2. We can use the Kyle's lambda as proxy of liquidity. Note that several measures of liquidity or illiquidity are available in the financial literature.

Note 3. See Mamoghli and Henchiri (2002).

Note 4. If autoregressive conditional heteroskedasticity effects are statistically significant, we will use aconditionally heteroscedastic volatility measure. 
Note 5. See Nijman, Palm and Wolff (1993).

Note 6. The forward-spot differential or the forward premium or the forward discount.

Note 7. It can be either a regressor to explain the return or an exogenous variable to explain the risk.

Note 8 . Let $\mathrm{spr}_{\mathrm{t}, \mathrm{i}}$ be the relative spread at time $\mathrm{t}$ for the $\mathrm{i}^{\text {th }}$ foreign currency. It is given by the following formula: $s p r_{t}=\frac{a s k_{t, i}-b i d_{t, i}}{\frac{a s k_{t, i}+b i d_{t, i}}{2}}$

Note 9. Empirically, if the relative bid-ask spread is not stationary we will use the differenced time series to make them stationary and make our regressions estimations.

Note 10. It is the abbreviation of Autoregressive moving average. ARMA models assume a constant volatility and are conditionally and unconditionally homoskedastic. We use Box \& Jenkins methodology.

Note 11. Seemingly Unrelated Regressions.

Note 12. This class of regression models also called Zellner's model.

Note 13. If we observe a statistically significant correlation matrix between foreign exchange rates, it is better to use the SURE model.

Note 14. (G)ARCH-(M) models are unconditionally homoskedastic but conditionally heteroskedastic.

Note 15. Data are from Datastream, Paris Dauphine.

Note 16 . Given that the data is sampled daily and the differences are weekly (5 days).

Note 17. See Fama (1984).

Note 18. Equation (1) represents the Fama's decomposition and equation (2) refers to our alternative decomposition.

Note 19. The exogenous and endogenous variables are not observed at the same time.

Note 20. These seven steps lead us to five comparisons which are: Comparison 1: We will compare results of step 1 vs those of step 2 and we will find out which step is better than the other. Let $\mathrm{B}\left(\mathrm{step}_{\mathrm{i}}, \mathrm{step}_{\mathrm{j}}\right)$ be the logical function : better than. Comparison 2: Step 3 vs B( $\left(\operatorname{step}_{1}, \mathrm{step}_{2}\right)$. Comparison 3: Step 4 vs B( step $\left._{3}, \mathrm{~B}\left(\mathrm{step}_{1}, \mathrm{step}_{2}\right)\right)$. Comparison 4 : Step 5 vs B( step $\left._{4}, \mathrm{~B}\left(\operatorname{step}_{3}, \mathrm{~B}\left(\operatorname{step}_{1}, \mathrm{step}_{2}\right)\right)\right)$. Finally, the comparison 5: Step 6 vs step 7.

Note 21. Augmented Dickey-Fuller (ADF), Phillips-Perron (PP) and Kwiatowski, Phillips, Schmidt and Shin (KPSS) unit root tests are run.

Note 22. All the empirical issues are made using EViews 6 software.

Note 23. In fact, we run only one of them given that they are equivalent. Then we estimate the regression equation (5).

Note 24. We estimate the underlying regression using least squares method and White heteroskedasticity-consistent standard errors and covariance.

Note 25 . Which is also an elasticity.

Note 26. The $\mathrm{R}^{2}$ is very small $(0.009225)$ which means that the dependent variable does not have a strong explanatory power but it explains significantly a little bit of the total information.Most of the information is not captured only by the forward premium which pushes us to look for extracting more information.In addition we have to check up residuals for eventual implied information.

Note 27. Equation (4.2).

Note 28. Our model selection is based on the following criteria $\mathrm{R}^{2}$, adjusted $\mathrm{R}^{2}$, $\log$ likelihood, Akaike information criterion (AIC) and Schwarz information criterion (SIC).

Note 29. Equations (7.1) and (7.2).

Note 30. Equations (7.3) and (7.4).

Note 31. For the ARCH (1) model, all coefficient estimates are statistically significant at $1 \%$ level except for the differenced relative bid-ask spread coefficient estimate which is reliably non zero at 5\% level..For the ARCH (1)-M model, all coefficient estimates are statistically significant at 1\% level except for the differenced relative bid-ask spread coefficient estimate which is significantly different from zero at $5 \%$ level.

Note 32. In both models: $\mathrm{ARCH}(1)$ and $\mathrm{ARCH}(1)-\mathrm{M}$. 
Note 33

$$
\begin{aligned}
& Y W G B P_{t+1}=a_{1, G B P}+a_{2, G B P} X W G B P_{t}+\varepsilon_{t+1, G B P} \\
& D W S G B P_{t+1}=a_{3, G B P}+a_{4, G B P} X W G B P_{t}+\mu_{t+1, G B P}
\end{aligned}
$$

Note 34 . See Table 4 below. The $\mathrm{R}^{2}$ is very small (0.002566) which means that the dependent variable does not have a strong explanatory power but it explains significantly a little bit of the total information.Most of the information is not captured only by the forward premium which pushes us to look for extracting more information. In addition we have to check up residuals for eventual implied information.

Note 35. See Note 33.

Note 36. The regression equation (4.2) taken for the EUR/GBP.

Note 37. See Table 5 below.

Note 38 . We can reliably deduce that our alternative regressions are coherent with Fama's regressions.

Note $39 . \mathrm{MA}(\mathrm{q}) / \mathrm{q} \geqq 2$ and $\operatorname{AR}(\mathrm{p}) / \mathrm{p} \geqq 1$.

Note 40. Equations (10.1) and (10.2). All coefficient estimates are statistically significant at $1 \%$ level.

Note 41. Equations (11.1) and (11.2).

Note 42 . For the EUR/JPY.

Note 43 . We find out that the coefficient of determination, $\mathrm{R}^{2}$, is negative which implies a model misspecification. In fact, that means the statistical insignificance of the forward premium as an explanatory variable. So it follows that the forward-spot differential is not statistically a significant determinant in the case of the EUR/JPY.

Note 44. This empirical finding shows up reliably why the forward premium in EUR/JPY does not have an explanatory power in the Fama's regression. Given the statistically significant constancy of the forward-spot differential, it will no longer be considered as a determinant in the case of the EUR/JPY.

Note 45. We use the same criteria for model selection as in the cases of the EUR/USD and EUR/GBP.

Note 46. Of order 1.

Note 47. DZJPY is statistically significant at 5\% level as a regressor in the mean equation in a model that does not outperform the MA(4)-ARCH(1) model.

Note 48. Fama's decomposition is given by equation (1) and our alternative decomposition is given by equation (2).

Note 49.

$f_{t, 1, i}-S_{t+1, i}:\left(\begin{array}{ccc}1 & 0.568887 & 0.583798 \\ 0.568887 & 1 & 0.444726 \\ 0.583798 & 0.444726 & 1\end{array}\right) ; f_{t, 1, i}-S_{t, i}:\left(\begin{array}{ccc}1 & 0.681156 & 0.178584 \\ 0.681156 & 1 & 0.482361 \\ 0.178584 & 0.482361 & 1\end{array}\right) ; S_{t+1, i}-$
$S_{t, i}:\left(\begin{array}{cccccc}1 & 0.567908 & 0.586075 \\ 0.567908 & 1 & 0.445141 \\ 0.586075 & 0.445141 & 1\end{array}\right) ; s p r_{t+1, i}-s p r_{t, i}:\left(\begin{array}{ccc}1 & 0.677239 & 0.703487 \\ 0.677239 & 1 & 0.510897 \\ 0.703487 & 0.510897 & 1\end{array}\right)$.

Note 50. Greater than one.

Note 51. $\tilde{d}_{4, U S D}=\widetilde{d}_{4, G B P}$.

Note 52 . The statistical equality of the slope coefficient estimates. 